\title{
A Base Nacional Comum Curricular e a Educação Básica
}

\author{
Lucas Portilho Nicoletti ${ }^{1}$ \\ Cesar Adriano Ribeiro Nunes ${ }^{2}$ \\ Arlete Guisso Scaramuzza Portilho Nicoletti ${ }^{3}$
}

\begin{abstract}
RESUMO
A Base Nacional Comum Curricular é um documento normativo, voltado para a construção de currículos e propostas pedagógicas na Educação Básica. Trabalha com os conceitos de aprendizagens essenciais, competências e educação integral. Tem por objetivo diminuir as desigualdades educacionais e sociais no imenso território brasileiro, via educação, colocando o estudante no centro de todo o processo educacional. A Base sofre inúmeras críticas de diversos setores e atores, porém é um documento homologado pelo Ministério da Educação e deve ser cumprido. A Educação Básica está dividida em três etapas: Educação Infantil, Ensino Fundamental e Ensino Médio, oito modalidades de ensino e três princípios norteadores. As escolas de Educação Básica precisam construir seus currículos, suas propostas e práticas pedagógicas a partir deste novo marco referencial, mesmo observando que nenhum
\end{abstract}

\footnotetext{
${ }^{1}$ Licenciado em Educação Física pela Escola de Educação Física e Esporte da Universidade de São Paulo (1993). Mestre em Ciências da Motricidade pela Universidade Estadual Paulista Júlio de Mesquita Filho (2003). Doutor em Educação junto à Faculdade de Educação, na área de concentração Filosofia e História da Educação, eixo de pesquisa, estudo e trabalho Ética, Política e Educação e grupo de estudo PAIDEIA, da Universidade Estadual de Campinas - UNICAMP (2017). Pós-doutorado em andamento junto à Faculdade de Educação - UNICAMP (2020). Licenciado em Pedagogia pelo Claretiano Centro Universitário (2020). Atualmente é professor do Curso de Licenciatura e Bacharelado em Educação Física e do Programa de Pós-graduação em Educação - Mestrado Acadêmico - da Universidade Estadual de Roraima. Orcid ID: https://orcid.org/0000-0003-1069-2728 ${ }^{2}$ Bacharel em Educação Física pelo Centro Universitário Anhanguera (2012). Licenciado em Educação Física pelo Centro Universitário Anhanguera (2014). Especialista em Gestão Esportiva pelo Centro Universitário Claretiano (2013). Mestre em Educação, na área de Psicologia e Educação na Universidade Estadual de Campinas - UNICAMP (2019), licenciado em Pedagogia pelo Centro Universitário Claretiano (2020). Foi Coordenador de Esportes no Colégio Dom Inácio de Educação Básica (Guaxupé-MG) e docente no Centro Universitário da Fundação Educacional Guaxupé (UNIFEG) por cinco anos (2016 a 2020).

${ }^{3}$ Licenciada em Pedagogia pela Faculdade Riopretense de Filosofia, Ciências e Letras (1989). Pós-graduada em Psicopedagogia pelo Claretiano- Centro Universitário (2018) Especialista em Psicologia da Saúde Mental pelo Centro Brasileiro de Pesquisa em Saúde Mental (1984). Mestra em Desenvolvimento Humano e Tecnologias pela Universidade Estadual Paulista Júlio de Mesquita Filho (2015). Coach pelo Instituto Brasileiro de Coaching (2018). Fundadora e coordenadora pedagógica do Núcleo de Pesquisa em Educação Indígena de Roraima. Diretora Pedagógica do Colégio Zerbini- COOPEN e professora afastada da Faculdade de Educação, Ciências e Artes Dom Bosco de Monte Aprazível.
} 
professor ou professora que atua no nível escolar da Educação Básica teve sua formação inicial pautada nos paradigmas da BNCC. Neste sentido, o nosso objetivo central é apresentar e discutir a Base Nacional Comum Curricular, enquanto documento normativo, além de caracterizar a Educação Básica.

Palavras-chave: Base Nacional Comum Curricular. Educação Básica. Currículo.

\section{RESUMEN}

La Base Nacional Común Curricular (BNCC) es un documento normativo orientado a la construcción de currículos y propuestas pedagógicas en la Educación Básica. Comprende los conceptos de aprendizajes esenciales, aptitudes y educación integral. Con el estudiante en el centro de todo el proceso educativo, su objetivo es disminuir las desigualdades educacionales y sociales en el inmenso territorio brasileño por medio de la educación. La Base sufre innumerables críticas desde variados sectores y agentes educativos, pero es un documento homologado por el Ministerio de la Educación e debe de ser obedecido. La Educación Básica está dividida en tres partes: Educación Infantil, Enseñanza Fundamental (primaria) y Enseñanza Media (secundaria). Además, hay ocho modalidades de enseñanza y tres principios rectores. Las escuelas de Educación Básica tienen que construir sus currículos, propuestas y prácticas pedagógicas a partir de este nuevo referente, aun notando que ningún docente que labora en el nivel escolar de Educación Básica tuvo su formación inicial basada en los paradigmas del BNCC. En este sentido, nuestro objetivo central es presentar y discutir el Base Nacional Común Curricular, como documento normativo, además de caracterizar la Educación Básica.

Palabras-clave: Base Nacional Común Curricular. Educación Básica. Currículo.

\section{Introdução}

Este texto tem como objetivo central apresentar e discutir a Base Nacional Comum Curricular (BNCC), a partir do axioma de que ela é um documento normativo, além de caracterizar a Educação Básica como um dos níveis escolares estabelecidos pela Lei de Diretrizes e Bases da Educação Nacional (LDBEN) vigente. Portanto, expõe ideias e pontos de vista de determinados autores e autoras sobre os objetos anunciados, com base em pesquisas referenciais e em considerações finais provisórias, garantindo sua originalidade.

Em resposta ao que prevê a Constituição da República Federativa do Brasil (CF) de 1988, em seu Artigo 210, a Lei de Diretrizes e Bases da Educação Nacional (LDBEN) de 1996, em seu Artigo 26, as Diretrizes Curriculares Nacionais Gerais da Educação Básica (DCNGEB), 2013 e o Plano Nacional de Educação (PNE), 2014 (Silva e Santos, 2018), o Ministério da Educação (ME) homologou, através da Portaria n 1570, de 20 de dezembro de 2017, a Base Nacional Comum Curricular (BNCC). Após dois dias, mais precisamente em 
22 de dezembro de 2017, o Conselho Pleno (CP) do Conselho Nacional de Educação (CNE) emitiu a Resolução ${ }^{\circ}$ 02, que instituiu e orientou a implantação da BNCC.

Sinalizamos que o movimento de criação da BNCC teve seu início efetivo com a publicação da Portaria n 592, de 17 de junho de 2015, que instituiu a Comissão de Especialistas para a elaboração da Base Nacional Comum Curricular, isso ainda no governo da então Presidenta Dilma Vana Rousseff e do Ministro da Educação Prof. Dr. Renato Janine Ribeiro.

Nota-se que neste período histórico ainda o ME e CNE eram compostos por representantes de muitos segmentos da sociedade brasileira, conferindo-lhe a pluralidade de ideias e concepções característico do sistema democrático, fato que deixou de existir no dia 31 de agosto de 2016, com o impeachment controverso da única Presidenta eleita democraticamente pelo povo brasileiro (AGUIAR, 2019).

Em resposta ao afastamento definitivo da Presidenta pelo Congresso Nacional assume o então vice-presidente da República, Michel Miguel Elias Temer Lulia, político de carreira e representante dos seguimentos neoliberais. Ele interrompe as políticas públicas sensíveis as demandas da sociedade civil e impõe, com o apoio do Congresso Nacional, reformas terríveis e questionáveis, como a Emenda Constitucional 954, conhecida como PEC dos Gastos.

Findado o governo de Michel Temer em 01 de janeiro de 2019, o processo eleitoral presidencial de 2018 revela contradições profundas na sociedade brasileira, pois o novo presidente da República eleito é o candidato Jair Messias Bolsonaro. O resultado da votação apresenta uma clara divisão do país, pois $55,13 \%$ dos eleitores votaram em Bolsonaro, enquanto $44,87 \%$ votaram em Haddad.

A eleição de Bolsonaro lança indubitavelmente o país ao caos, já que todo o discurso do atual presidente incita a violência, o descrédito nas instituições democráticas, a negação da ciência e o total desrespeito a vida. Isto fica evidente ainda mais durante a Pandemia do novo Coronavírus, causador da doença COVID-19, a partir da inoperância intencional na aquisição das vacinas e na ausência de coordenação federal para enfrentar a Pandemia.

Apresentada esta pequena contextualização, podemos observar que o processo de criação da BNCC foi longo, trabalhoso e, por muitas vezes, conflituoso, pois atravessou vários governos e concepções do mundo, de vida, de ser humano e de educação distintas. Mesmo assim, em 17 de junho de 2015, o Ministério da Educação, através da Portaria ${ }^{\circ}$ 592, institui Comissão de Especialistas para a Elaboração de Proposta da Base Nacional Comum Curricular.

\footnotetext{
${ }^{4}$ A Emenda Constitucional 95 foi aprovada pelo Congresso Nacional em 15 de dezembro de 2016. Sua pior consequência se refere ao congelamento por 20 anos dos investimentos em Saúde e Educação, vinculando o reajuste no repasse de verbas à inflação do ano anterior. Saúde e Educação, dois dos setores mais delicados da sociedade brasileira sofrerão os impactos desta EC que comprometerá o acesso da população brasileira a estes setores essenciais e a sua qualidade na prestação dos serviços.
} 
Na sequência, em 16 de setembro de 2015, a $1^{\text {a }}$ versão da BNCC foi disponibilizada como fruto do trabalho intenso desenvolvido pela Comissão de Especialistas nomeada. A contar deste momento as escolas, a sociedade civil, as instituições e qualquer cidadão teriam a oportunidade de contribuir sugerindo objetivos, conteúdos, procedimentos e processos avaliativos que julgassem pertinentes e necessários à BNCC.

Dando prosseguimento ao processo, em 03 de maio de 2016 a $2^{a}$ versão da BNCC foi disponibilizada, lembrando que ela representava o "[...] fruto de amplo processo de debate e negociação com diferentes atores do campo educacional e com a sociedade brasileira em geral [...]" (BRASIL, p. 24, 2016).

Seguindo o processo de construção compartilhada, de 23 de junho a 10 de agosto de 2016, ocorreram vinte e sete seminários estaduais com o objetivo de debater a $2^{\mathrm{a}}$ versão da BNCC. Participaram destes seminários professores, gestores e especialistas, totalizando 9275 participantes em mais de 50 palestras. Todas as regiões do país foram representadas e vinte e sete plenárias de consolidação realizadas (Brasil, 2016). Em agosto do mesmo ano, iniciou-se a redação da $3^{a}$ versão.

Em abril de 2017, o ME passou às mãos do CNE a $3^{a}$ versão da BNCC (Neira, 2018). O CNE elaborou Parecer e projeto de Resolução que foram remetidos ao Ministério da Educação para homologação. Salientamos que a partir da homologação foi dado andamento à formação e capacitação dos professores e o suporte aos Sistemas Municipais e Estaduais de Educação para a composição e regulação dos novos currículos escolares.

Destacamos que as primeiras etapas da Educação Básica (EB) homologadas pelo Ministério da Educação, com Parecer e Resolução do CNE em 2017, referem-se apenas à Educação Infantil e ao Ensino Fundamental. Este fato, segundo Callegari (2019), Tuttman e Aguiar (2019), implicou na ruptura do conceito de Educação Básica incluído na LDB de 1996, fruto de intensa luta da sociedade civil organizada, pois deixou de fora o Ensino Médio.

As advertências quanto ao rompimento da Educação Básica foram desconsideradas e em 06 de março de 2018 aconteceu o Dia D da Base, no qual os educadores e demais sujeitos envolvidos com a Educação Nacional (EN) se reuniram para estudar e compreender sua implementação e os possíveis impactos na Educação Básica, recordando que apenas a Educação Infantil e o Ensino Fundamental estavam representados na BNCC neste momento.

No dia 02 de abril de 2018, o ME confiou novamente ao CNE a $3^{\text {a }}$ versão da BNCC referente ao Ensino Médio (EM), dando início a um processo de audiências públicas e debates. Em 05 de abril, foi instituído o Programa de Apoio à Implementação da Base Nacional Comum Curricular (ProBNCC) e em 02 de agosto de 2018, as escolas brasileiras se mobilizaram para debater e propor como atuar com a BNCC do EM. Foram criados comitês de discussão para que professores, técnicos educacionais e gestores pudessem argumentar e sugerir ideias para o aperfeiçoamento da Base.

Por fim, após praticamente um ano de intensos debates e discussões, em 14 de de- 
zembro de 2018, o ME homologou a Base Nacional Comum Curricular para a etapa do Ensino Médio. Atualmente, todas as etapas da Educação Básica estão contempladas no documento, que é referência nacional para a construção dos currículos dos sistemas (federal, estadual, municipal e o Distrito Federal) e das redes escolares vinculadas aos Estados, Municípios e ao Distrito Federal.

Falando em currículos ${ }^{5}$ escolares, consideramos tratar da EB brasileira, ainda que de forma sucinta, nesta introdução. Atualmente a EB está dividida em três etapas de escolarização: a Educação Infantil, que recebe crianças de zero a cinco anos de idade, o Ensino Fundamental, cujos frequentadores possuem a idade entre seis e quatorze anos e o Ensino Médio, adolescentes entre quinze e dezessete anos.

Observamos, contudo, que as faixas etárias indicadas referentes à relação etapa/idade tendem a ser bastante diferentes no Brasil, uma vez que as diferenças socioeconômicas e culturais causam impactos profundos nesta relação. É justamente por essa razão que as Diretrizes Curriculares Nacionais Gerais para a Educação Básica apresentam um texto diferente quando tratam da etapa Ensino Fundame ntal: "[...] com duração de 9 (nove) anos, é organizado e tratado em duas fases: a dos 5 (cinco) anos iniciais e a dos 4 (quatro) anos finais" e do Ensino Médio: "[...] com duração mínima de 3 (três) anos" (BRASIL, p. 36, 2013).

Outro ponto que merece ser indicado gira em torno das oito modalidades previstas nas DCNGEB. A Educação de Jovens e Adultos (EJA), A Educação Especial na Perspectiva Inclusiva, a Educação do Campo, a Educação Escolar Indígena, a Educação Escolar QuiIombola, a Educação Profissional e Tecnológica, a Educação a Distância e a Educação nos Estabelecimentos Penais. Todas as oito modalidades vêm como resposta a uma demanda histórica destes sujeitos que foram colocados em uma situação de quase invisibilidade, sem reconhecimento de suas identidades e respeito pelo seu modo de vida.

Um exemplo clássico e possível de ser apontado se refere à Educação Indígena,

[...] que logrou conquistas importantes nos últimos 30 anos, com o aumento da cobertura de atendimento nos anos iniciais do Ensino Fundamental, a criação de programas de formação de professores indígenas, a elaboração e o uso de livros didáticos bilíngues e os avanços normativos relacionados às novas perspectivas pedagógicas de uma Educação escolar específica e diferenciada (BANIWA, 2019, p. 38-39).

Assim, ao levarmos em consideração que a EB possui a intenção de alargar as possibilidades de qualquer educando no sentido de oferecer-lhe uma formação comum, essencial

\footnotetext{
${ }^{5}$ Concebemos o currículo escolar como um conjunto de práticas que buscam articular as experiências e os saberes dos estudantes com os conhecimentos que fazem parte do patrimônio cultural, artístico, ambiental, científico e tecnológico produzido historicamente pela humanidade, de modo a promover o desenvolvimento integral das crianças, adolescentes, jovens e adultos, contribuindo para a construção de suas identidades.
} 
para o exercício da cidadania, para que possa progredir no trabalho e nos estudos que porventura intente desenvolver, a inclusão das oito modalidades permite que os grupos e seus sujeitos almejem ser mais ${ }^{6}$.

Neste sentido, corroboramos com as DCNGEB quando ela declara e sustenta que a EB é um direito universal e base imprescindível para o exercício pleno do direito à cidadania. Durante a EB o sujeito desenvolve condições para construir e reconstruir constantemente sua identidade, pois é evidente que ocorrem inúmeras modificações cognitivas, sociais, emocionais, corporais e culturais. É neste período de profundas transformações, neste tempo, neste espaço e no contexto em que está inserido, que ele poderá adquirir compreensão sobre a pluralidade presente no Mundo e a urgência de liberdade para que esta pluralidade se manifeste.

A partir da premissa na qual pluralidade e liberdade coabitam o mesmo espaço, como condição essencial para a existência de cada uma delas e desenvolvimento dos estudantes, toda a ação educativa deve estar pautada no respeito incondicional aos tempos, períodos e fases dos estudantes. Isto precisa definitivamente ser um princípio orientador.

Torna-se, em tese, compromisso abertamente assumido, também, pelos sistemas educacionais, gerar as condições mínimas obrigatórias para a superação das diferenças socioeconômicas e culturais existentes no Brasil e, assim, oportunizar às crianças, aos adolescentes e aos adultos acesso e permanência à escola, aprendizagem e desenvolvimento, construindo com estes sua formação de forma dialogada e no período correspondente à relação etapa/ idade.

Lembramos sempre que o respeito à pluralidade e à liberdade precisam ser seguidos em função das diferentes condições sociais, culturais, físicas, sensoriais, emocionais, de crenças, de gêneros e étnicas dos estudantes.

\section{O Percurso}

Ao tratarmos do processo de construção da Base Nacional Comum Curricular na introdução, esperamos ter sido capazes de dar uma ideia cronológica do curso seguido. A partir deste momento, pretendemos focar com mais profundidade no próprio documento e cotejá-lo com alguns autores, quer sejam eles defensores ou críticos contumazes dele.

Na sequência, abordaremos a Educação Básica nos debruçando especificamente nas DCNGEB, de forma a apontar alguns elementos essenciais relativos à Educação Infantil (EI), ao Ensino Fundamental (EF), ao Ensino Médio (EM), às modalidades de ensino e, por fim,

\footnotetext{
${ }^{6}$ Ser mais é uma expressão forjada por Paulo Freire e se refere à vocação ontológica e histórica dos seres humanos, no sentido de terem e reconhecerem o seu direito e o direito do outro por uma vida mais digna e, assim, transformar injustiça em justiça, ignorância em conhecimento, ódio em amor, morte em vida, não pertencimento em pertencimento.
} 
aos princípios que norteiam todas as ações pedagógicas na escola.

\section{A Base Nacional Comum Curricular}

De acordo com Neira (2018) existe em curso hoje no Brasil uma política educacional que objetiva a consolidação de um determinado projeto de sociedade, centrado em princípios tecnocráticos e na racionalidade técnica, em detrimento à criticidade. Este projeto representa mais uma investida de setores conservadores e reacionários, basta observar o congelamento dos recursos destinados às políticas públicas, o aumento do desemprego, a queda do Produto Interno Bruto (PIB), da produção industrial e a desconstrução constante dos direitos trabalhistas, previdenciários e sociais (POLLI, 2018; NUNES, 2019; TAGLIAVINI, 2019).

Já Silva e Santos (2018) questionam os motivos que levaram à criação da BNCC. Para eles, atender à legislação educacional e vincular a Base ao aumento na qualidade da Educação não parece consistente, pois acreditam que o Brasil já possui uma gama de leis suficientes destinadas à Educação e propor um novo marco normativo seria assumir que tais leis são inoperantes e ineficientes.

Quanto à melhora na qualidade da Educação, afirmam que ela é cercada por diversos interesses e recebe inúmeras demandas. A política salarial, a política de formação inicial e continuada dos professores e a recuperação e ampliação da infraestrutura das escolas são reflexos destes interesses. Consideram inviável o "sucesso" da Base em função da aprovação da Emenda Constitucional 95/2016 (EC 95/2016) que limitou os gastos públicos, inclusive dos gastos com a Educação, até 2036. Para eles, a Base já nasce morta, pois as condições objetivas imprescindíveis para viabilizar o salto qualitativo da educação nacional não são efetivadas.

Além disso, identificam a Base como um instrumento de controle, pois ela regulará o currículo escolar e, obviamente, o trabalho do professor, uma vez que estabelecerá o que deve ou não ser ensinado, como fazê-lo, em que momento e como avaliar. Tudo a partir dos conteúdos mínimos, das competências e das habilidades. Questionam o anunciado pelo documento quanto à redução das desigualdades educacionais e sociais, porque entendem que estas desigualdades são frutos amargos da construção histórica, econômica, política e social de segregação da maior parte da população. Apontam que hierarquizar e igualar os objetos de ensino e de aprendizagem tendem a distanciar ainda mais os sujeitos dos conhecimentos. Portanto, não concordam com um currículo único nacional em função das dimensões territoriais, da diversidade cultural e das imensas desigualdades sociais existentes (SILVA E SANTOS, 2018).

Continuando as críticas, Cericato e Cericato (2018) garantem que o setor privado, de forma organizada e por meio da pressão dos empresários, influenciou de forma incisiva a construção da BNCC. Este grupo tem por objetivo, em tese, tornar o Brasil competitivo internacionalmente e para isso precisou delinear um projeto de formação voltado ao mercado de trabalho, tendo como mão de obra, principalmente, o sujeito pobre, carente das condições 
mínimas essenciais a uma vida digna.

Por este ponto de vista não é possível a existência de uma formação mais humana, que integre conhecimentos científicos e culturais. E como se não bastassem todos estes argumentos a escola tornou-se um nicho de mercado promissor, com espaços altamente lucrativos, movimentando o mercado de livros, de apostilas, de formação de professores e de gestão educacional à luz deste novo modelo de Educação. Prova disso é a apresentação da proposta de revisão das Diretrizes Curriculares Nacionais para os Cursos de Pedagogia, divulgada pelo Conselho Nacional de Educação em 10 de fevereiro de 2021.

Esta proposta ataca as Faculdades de Educação, compromete a investigação científica no campo da Educação e da Pedagogia e a formação inicial dos docentes que atuarão na Educação Básica, na medida em que fragmenta a formação docente, estabelece a centralidade da concepção de caráter técnico-instrumental, divide os percursos formativos dos futuros docentes que atuarão na Educação Infantil e Ensino Fundamental I, daqueles que atuarão no Ensino Fundamental II e Ensino Médio, além de exigir outra formação para a gestão escolar, coordenação pedagógica e orientação educacional.

Estas referências apontadas acima tendem a promover o rompimento da ideia de formação da infância compreendida do zero aos dez anos, produzem desigualdades entre os profissionais da educação no seio da escola e inviabiliza a gestão democrática como princípio. Outro fato marcante nesta iniciativa é a volta do conceito de currículo mínimo, controlador do que e do como se ensina, negligenciando a LDB e concepção de diretrizes curriculares.

Surge mais uma crítica no sentido de se reconhecer o problema da desigualdade no acesso ao conhecimento. Isto impossibilita a construção da qualidade educacional proclamada pela BNCC e apenas poderá ser enfrentado de forma a materializá-la se forem discutidos de forma sistematizada, dialógica e profunda o currículo, a política, o sistema econômico e a formação do professor (CASAGRANDE; ALONSO; SILVA, 2019).

Apesar das críticas existirem e fazerem sentido em função do referencial epistemológico, político e pedagógico adotados, corroboramos com Cericato e Cericato (2018) quando afirmam que a nossa discussão é em torno de como a formação de professores e formação continuada de professores podem ser pensadas e propostas a partir da BNCC, já que ela está posta, e os professores precisam de tempo, de orientação e de estudo para construírem e reconstruírem suas práticas alicerçadas neste novo referencial normativo.

Desta maneira, conforme atesta Brasil (2018, p. 7) a Base Nacional Comum Curricular é

[...] um documento de caráter normativo que define o conjunto orgânico e progressivo de aprendizagens essenciais que todos os alunos devem desenvolver ao longo das etapas e modalidades da Educação Básica, de modo a que tenham assegurados seus direitos de aprendizagem e desenvolvimento [...]. Este documento normativo aplica-se exclusivamente à educação escolar [...], e está orientado pelos princípios éticos, políticos e estéticos que visam à formação humana integral e à construção de uma sociedade justa, democrática e inclusiva [...]. 
Sendo um referencial nacional normativo, portanto, obrigatório, determinará a construção dos currículos dos sistemas e das redes escolares dos Estados, do Distrito Federal e dos Municípios e, consequentemente, as propostas pedagógicas das instituições escolares, que deverão apresentar claramente um conjunto de aprendizagens essenciais, destinadas aos estudantes para seu desenvolvimento integral, através de dez competências ${ }^{7}$ gerais (BRASIL, 2018).

Novamente trazemos à tona a questão da Educação Indígena, pois esta modalidade de ensino peculiar pretende elucidar que

[...] os currículos das escolas indígenas exigem a participação ativa das lideranças de cada povo, dos professores indígenas e das comunidades, respeitando o desejo de cada grupo, em busca de uma Educação que valorize suas políticas culturais e permita o acesso ao conhecimento e às práticas de outros grupos sociais (MENEZES, 2019, p. 126).

Destarte, certamente a BNCC sugestionará os currículos que, conforme admite Deschamps (2019), precisam evidenciar claramente os objetivos de aprendizagem a serem atingidos pelos estudantes ao final do processo de escolarização. Além disso, os currículos destinados à formação inicial, à formação continuada, à elaboração de materiais didáticos, às matrizes de avaliação e exames nacionais, que serão, pelo menos teoricamente, pensados a luz deste referencial, também sofrerão influência significativa da Base.

Recordamos, nesta ótica, que a BNCC compõe a política nacional da Educação Básica e pretende apoiar as políticas e ações alusivas à formação inicial e continuada de professores, à avaliação, à elaboração de conteúdos educacionais e aos critérios para a oferta de infraestrutura adequada e necessária para o integral desenvolvimento do processo educacional.

Callegari (2019) afirma que a Base é concebida como um instrumento capaz de explicitar os deveres do Estado e da sociedade com a Educação, de forma a promover a equidade e estimular a elaboração dos currículos escolares, a formação inicial e continuada de professores, a produção de materiais didáticos, os processos de avaliações e a própria articulação de um Sistema Nacional de Educação.

A BNCC acredita ser um instrumento capital para que seja transposta a fragmentação das políticas educacionais, para o revigoramento do regime de colaboração entre as três esferas de governo e para a potencialização da tão proclamada qualidade da Educação, na medida em que o acesso e a permanência do estudante na escola seja uma realidade e que haja aprendizagem minimamente necessária e significativa.

\footnotetext{
${ }^{7}$ A BNCC define competência "como a mobilização de conhecimentos (conceitos e procedimentos), habilidades (práticas, cognitivas e socioemocionais), atitudes e valores para resolver demandas complexas da vida cotidiana, do pleno exercício da cidadania e do mundo do trabalho".
} 
Neste sentido, a aprendizagem minimamente necessária, também chamada de aprendizagem essencial é pautada em dez competências gerais, que estabelecem diálogo e se estendem didaticamente pelas três etapas da Educação Básica, que construindo conhecimento, desenvolvendo habilidades e formando atitudes e valores, corporificam os direitos de aprendizagem e desenvolvimento.

Segundo Cericato e Cericato (2018) e Casagrande, Alonso e Silva (2019), são estas as dez competências gerais propostas pela BNCC para a EB: conhecimento, pensamento científico, crítico e criativo, senso estético, comunicação, argumentação, cultura digital, autogestão, autoconhecimento e autocuidado, empatia e cooperação, por fim, autonomia.

Contudo, para sermos um pouco mais específicos nos apoiaremos no texto original, da versão final, da BNCC. Ele traz as seguintes explicações quanto às dez competências gerais da Educação Básica:

1. Valorizar e utilizar os conhecimentos historicamente construídos sobre o mundo físico, social, cultural e digital para entender e explicar a realidade, continuar aprendendo e colaborar para a construção de uma sociedade justa, democrática e inclusiva.

2. Exercitar a curiosidade intelectual e recorrer à abordagem própria das ciências, incluindo a investigação, a reflexão, a análise crítica, a imaginação e a criatividade, para investigar causas, elaborar e testar hipóteses, formular e resolver problemas e criar soluções (inclusive tecnológicas) com base nos conhecimentos das diferentes áreas.

3. Valorizar e fruir as diversas manifestações artísticas e culturais, das locais às mundiais, e também participar de práticas diversificadas da produção artístico-cultural.

4. Utilizar diferentes linguagens - verbal (oral ou visual-motora, como Libras, e escrita), corporal, visual, sonora e digital -, bem como conhecimentos das linguagens artística, matemática e científica, para se expressar e partilhar informações, experiências, ideias e sentimentos em diferentes contextos e produzir sentidos que levem ao entendimento mútuo.

5. Compreender, utilizar e criar tecnologias digitais de informação e comunicação de forma crítica, significativa, reflexiva e ética nas diversas práticas sociais (incluindo as escolares) para se comunicar, acessar e disseminar informações, produzir conhecimentos, resolver problemas e exercer protagonismo e autoria na vida pessoal e coletiva.

6. Valorizar a diversidade de saberes e vivências culturais e apropriar-se de conhecimentos e experiências que lhe possibilitem entender as relações próprias do mundo do trabalho e fazer escolhas alinhadas ao exercício da cidadania e ao seu projeto de vida, com liberdade, autonomia, consciência crítica e responsabilidade.

7. Argumentar com base em fatos, dados e informações confiáveis, para formular, negociar e defender ideias, pontos de vista e decisões comuns que respeitem e promovam os direitos humanos, a consciência socioambiental e o consumo responsável em âmbito local, regional e global, com posicionamento ético em relação ao cuidado de si mesmo, dos outros e do planeta.

8. Conhecer-se, apreciar-se e cuidar de sua saúde física e emocional, compreendendo-se na diversidade humana e reconhecendo suas emoções e as dos outros, com autocrítica e capacidade para lidar com elas.

9. Exercitar a empatia, o diálogo, a resolução de conflitos e a cooperação, fazendo-se respeitar e promovendo o respeito ao outro e aos direitos humanos, com acolhimento 
e valorização da diversidade de indivíduos e de grupos sociais, seus saberes, identidades, culturas e potencialidades, sem preconceitos de qualquer natureza.

10. Agir pessoal e coletivamente com autonomia, responsabilidade, flexibilidade, resiliência e determinação, tomando decisões com base em princípios éticos, democráticos, inclusivos, sustentáveis e solidários (BRASIL, p. 9-10, 2018).

Vejamos que não é de hoje que o termo competência aparece no referencial educacional recente adotado no Brasil. Desde a promulgação da $3^{a}$ LDBEN, no ano de 1996, passando pelo Referencial Curricular Nacional para a Educação Infantil, 1998 e pelos Parâmetros Curriculares Nacionais, 1997, 1998 e 1999, os Estados e municípios brasileiros têm pautado a construção de seus currículos a partir deste termo, visto que as avaliações nacionais e internacionais também o utilizam.

Isto evidencia que toda e qualquer decisão pedagógica deverá ser norteada para o desenvolvimento das dez competências. Admite-se que as aprendizagens essenciais, para serem amplamente fortalecidas, precisam reconhecer que os estudantes devem saber e saber fazer, por meio de conhecimentos, habilidades, atitudes, valores, na esfera conceitual, e a mobilização destes conceitos para enfrentarem as mais variadas exigências da vida cotidiana, do viver a cidadania e do mundo do trabalho.

Já que o Mundo contemporâneo pede uma resposta à altura das necessidades, quer sejam necessidades dos sujeitos ou do próprio Mundo, ter um referencial educacional que se disponibiliza a uma Educação integral ${ }^{8}$ pode ser considerado um avanço, principalmente por conta da enorme diversidade observada na sociedade brasileira.

Refletir e propor ações para todos os sujeitos, principalmente àqueles que nas últimas décadas têm ficado à sombra (indígenas, negros, deficientes, LGBTQI+ e idosos) é um avanço considerável e necessário para o fortalecimento de uma sociedade inclusiva, democrática, não discriminatória, não preconceituosa e que respeite as diferenças. Isto implica identificar e reconhecer diferentes infâncias, juventudes, culturas e a viabilidade de reinvenção constante de novas formas de ser e estar no Mundo. Uma sociedade plural para ser construída precisa de uma Educação integral.

Por consequência, esta forma de ver a Educação pretende efetivar a

[...] superação da fragmentação radicalmente disciplinar do conhecimento, o estímulo à sua aplicação na vida real, a importância do contexto para dar sentido ao que se aprende e o protagonismo do estudante em sua aprendizagem e na construção de seu projeto de vida (BRASIL, 2018, p. 15).

\footnotetext{
${ }^{8}$ Educação integral aqui se refere à construção de processos educativos de maneira intencional que promovam as mais variadas formas de aprendizagens, em sintonia com as necessidades, as possibilidades e os interesses dos estudantes e com os desafios da sociedade contemporânea.
} 


\title{
3. A Educação Básica
}

Direito assegurado pela Constituição Federal, pela Lei de Diretrizes e Bases da Educação Nacional e pelo Estatuto da Criança e do Adolescente (ECA), a Educação Básica de qualidade representa um eixo indispensável para o exercício integral da cidadania e acesso aos direitos sociais, civis, políticos e econômicos. Acreditamos que a Educação precisa viabilizar ao ser humano seu desenvolvimento integral, realizado em condições de liberdade, respeito e valorização das diferenças.

Brasil (2017) assinala que é dever do Estado garantir a Educação escolar pública por meio da Educação Básica obrigatória e gratuita dos quatro aos dezessete anos, nas etapas da Educação Infantil, Ensino Fundamental e Ensino Médio, garantindo padrões mínimos de qualidade de ensino?.

Seguindo este raciocínio fica evidente que o foco central de todo o processo educativo deverá centralizar-se no estudante. É isso que determina Brasil (2013, p. 35)

\begin{abstract}
Na Educação Básica, o respeito aos estudantes e a seus tempos mentais, socioemocionais, culturais, identitários, é um princípio orientador de toda a ação educativa. É responsabilidade dos sistemas educativos responderem pela criação de condições para que crianças, adolescentes, jovens e adultos, com sua diversidade (diferentes condições físicas, sensoriais e socioemocionais, origens, etnias, gênero, crenças, classes sociais, contexto sociocultural), tenham a oportunidade de receber a formação que corresponda à idade própria do percurso escolar, da Educação Infantil, ao Ensino Fundamental e ao Médio.
\end{abstract}

A Educação Infantil passou a integrar a EB a partir da LDBEN de 1996 e tem por objetivo contribuir de maneira efetiva no desenvolvimento integral das crianças de zero a cinco anos de idade, nas suas dimensões afetiva, social, motora, física e intelectual, adicionando a ação familiar e da comunidade.

O binômio cuidar e educar na El é condição visceral para o sucesso no desenvolvimento das crianças. Os dois eixos norteadores, interações e brincadeiras, devem compor as práticas pedagógicas, derivadas das propostas pedagógicas oriundas do currículo.

Nessa direção, é importante compreender que as propostas pedagógicas da Educação Infantil deverão considerar que a criança, centro do planejamento curricular, é sujeito histórico e de direitos que, nas interações, relações e práticas cotidianas que vivencia, constrói sua identidade pessoal e coletiva, brinca, imagina, fantasia, deseja, aprende, observa, experimenta, narra, questiona e constrói sentidos sobre a natureza e a sociedade, produzindo cultura.

O Ensino Fundamental é considerado por muitos a estrutura principal da EB e o foco da luta pelo direito à Educação. Atualmente ele tem nove anos de duração. A matrícula das

\footnotetext{
${ }^{9}$ Entendemos que os padrões mínimos de qualidade de ensino são definidos como a variedade e quantidade mínimas, por aluno, de insumos indispensáveis ao desenvolvimento do processo de ensino-aprendizagem.
} 
crianças deve ser feita aos seis anos e sua carga horária mínima é oitocentas horas, distribuídas em duzentos dias letivos (BRASIL, 2010).

Constantemente o EF gera inúmeras expectativas no sentido de oferecer uma Educação de melhor qualidade às crianças e aos adolescentes, por meio de maior financiamento, de programas de formação continuada destinados aos trabalhadores da Educação, de alterações curriculares, de novos projetos políticos pedagógicos e propostas pedagógicas em consonância com os enormes desafios da sociedade atual.

Os objetivos do EF estão em consonância com todos os marcos legais que regulam a Educação. Busca-se, portanto, o desenvolvimento dos estudantes, através da formação comum consistente para o exercício da cidadania, para o trabalho e para os estudos futuros. Contudo, conforme garante Baniwa (2019, p. 39) "[...] 25\% dos alunos matriculados não concluem e, portanto, não chegam ao Ensino Médio", o que indica, infelizmente, que muitas das mazelas históricas brasileiras relacionados à Educação e à construção de um país para todos ainda carece de um projeto político emancipatório, corajoso e ousado em busca de solução.

Mesmo assim, diante deste quadro absurdo de evasão e ainda sem contarmos o acesso restrito e a aprendizagem deficitária, o que impede substancialmente o exercício da cidadania, o trabalho digno e a continuidade dos estudos, espera-se que além da aquisição crítica dos conhecimentos históricos e culturalmente elaborados pela humanidade, valores como justiça, liberdade, solidariedade e dignidade acompanhem a formação dos estudantes para que eles contribuam, de forma intolerável, no combate aos preconceitos. Educação para a vida democrática é o que se espera.

O Ensino Médio é norteado pelos princípios específicos da formação integral do estudante, do projeto de vida, da pesquisa, do respeito aos direitos humanos, da compreensão da diversidade, da sustentabilidade ambiental, da diversificação e sua oferta, da indissociabilidade entre educação e prática social e entre teoria e prática (BRASIL, 2018).

O currículo deve ser construído com base nos direitos e objetivos de aprendizagens propostas pela BNCC, sendo as aprendizagens essenciais as que desenvolvem competências e habilidades, ou seja, conhecimento na ação.

Cada escola poderá ajustar a normatização imposta pela BNCC à sua realidade e fazer as adaptações necessárias dentro de seu contexto. As escolas construirão suas propostas pedagógicas pensando na seleção dos conhecimentos, tempos, arranjos alternativos, processos avaliativos e espaços, guiadas pelo princípio do pluralismo de ideias e de concepções pedagógicas, no exercício de sua autonomia e na gestão democrática.

As oito modalidades de ensino previstas poderão ser ofertadas em qualquer etapa escolar. É importante salientar que a inserção delas na EB representa a vitória de grupos progressistas, que historicamente travam batalhas no sentido de terem seus direitos reconhecidos e concretizados no "chão de escola".

A Educação de Jovens e Adultos (EJA) destina-se, sobretudo, a estudantes trabalhadores, com maior experiência de vida e maturidade. Segundo Martins (2019, p. 395) "A referida modalidade deve ser compreendida superando-se a concepção compensatória de recupera- 
ção de um tempo de escolaridade perdido e da aprendizagem como algo inerente à infância e à adolescência".

Ela representa o reconhecimento do Brasil no sentido de quitar um débito social para com os sujeitos que não puderam estudar na idade adequada, alusiva ao Ensino Fundamental e Médio, visto que encontramos graus variáveis de defasagem educacional, desde a total ausência de alfabetização, analfabetismo funcional ou incompleta escolarização. Isto mantém e reforça a exclusão social.

Nesta lógica, o EJA precisa ser flexível, tanto nos currículos, quanto nos tempos e espaços, pensando cursos e exames supletivos que possibilitem aos estudantes continuarem seus estudos em caráter regular, preferencialmente na modalidade Educação Profissional ligada à Educação Básica.

Mineiro (2020, p. 15) destaca que

[...] para refletir criticamente sobre a relevância da EJA, é necessário pensar sobre o discente jovem ou adulto em sua totalidade: resgatar a sua história de vida, associá-la ao saber cotidiano, e até mesmo identificar motivações que o levaram para a escola.

A Educação Especial na Perspectiva Inclusiva é uma modalidade de ensino transversal a todas as outras modalidades e etapas da Educação Básica. Ela deve se desenrolar preferencialmente na escola regular e ser prevista explicitamente nos Projetos Políticos Pedagógi$\cos$ (PPP) de cada unidade. Todos os estudantes com deficiências, transtornos globais de desenvolvimento, altas habilidades e/ou superdotação devem ter garantidas as condições para uma Educação de qualidade, por meio de Atendimento Educacional Especializado (AEE).

Matos (2020) afirma que a Política Nacional de Educação Especial na Perspectiva da Educação Inclusiva assinala que um de seus objetivos é "[...] assegurar a inclusão escolar de alunos com deficiência [...], orientando os sistemas de ensino para garantir: acesso ao ensino regular, com participação, aprendizagem e continuidade nos níveis mais elevados do ensino [...] (BRASIL, 2008, p. 14)".

Já o AEE objetiva reconhecer as habilidades e as limitações dos estudantes e coordenar recursos de acesso às atividades pedagógicas específicas em direção ao currículo. Os professores destas classes devem distinguir as habilidades e necessidades dos estudantes para organizar e orientar quais e como os recursos pedagógicos serão usados. Quanto aos professores das classes regulares, eles devem descobrir e incentivar os talentos dos estudantes, de forma interativa, inclusiva, interdisciplinar e dialógica.

A Educação do Campo tem sua identidade vinculada a questões inerentes à sua realidade, à memória coletiva, à rede de conhecimentos disponíveis, aos saberes próprios e à temporalidade dos estudantes. Toda a diversidade do campo, em todos os seus aspectos, deve estar prevista nas propostas pedagógicas das escolas. É responsabilidade das propostas pedagógicas organizarem metodologicamente o processo educacional de forma a acolher os estudantes. 
A Pedagogia da Terra busca fundamentar suas ações no princípio da sustentabilidade vislumbrando a preservação da vida. A Pedagogia da Alternância permite aos estudantes atuarem em dois ambientes formativos. Um de caráter escolar sistematizado, enquanto outro, de caráter laboral, e assim enfrentar situações de aprendizagens distintas, porém, complementares. Ambos os momentos/ambientes devem estar previstos no currículo. A ênfase na formação, ora em conhecimentos, ora em habilidades profissionais, ora em valores, atitudes e emoções estão presentes e são correlacionados.

Corroboram com o exposto Souza e Mendes (2012, p. 258) quando acentuam que

A organização dos tempos na escola do campo está fundamentada na alternância pedagógica, entendida como uma metodologia que combina períodos integrados de formação na escola e formação na família/comunidade, possibilitando a flexibilização da organização do trabalho pedagógico em alternâncias e adequando-o à realidade dos sujeitos educativos.

A Educação Escolar Indígena possui uma escola de característica singular, pois se insere no interior de suas terras e culturas diversas. Tal qual a Educação Quilombola, requer Pedagogia própria por conta da especificidade étnico-racial, já que cada povo ou comunidade possui muitas diferenças marcantes e formação docente específica.

As Escolas indígenas têm marcas, normas e ordenamentos jurídicos próprios, portanto, funcionam e se estruturam de forma peculiar. Têm ensino intercultural, bilíngue, pretendem valorizar plenamente cada cultura e certificar sua diversidade étnica.

É tão delicada, complexa e específica a formação dos professores indígenas que ela, além de ser desenvolvida no âmbito das instituições formadoras de professores, garante aos professores indígenas a sua formação em serviço e, também, se necessário, concomitantemente a sua própria escolarização.

A Educação Escolar Quilombola é direito e dever, no sentido de preservar a memória, afirmar a identidade negra e desenvolvê-la nas escolas localizadas em suas terras (Monteiro e Reis, 2019). Esta modalidade requer Pedagogia exclusiva por conta da especificidade cultural e étnico-racial de cada uma das comunidades. Ao se estruturar o funcionamento das escolas Quilombolas é imprescindível o reconhecimento, a valorização da diversidade cultural presente. Neste sentido, os professores precisam de formação específica, mas de acordo com os princípios que guiam a Educação Básica.

De acordo com Brasil (2019) existiam no território brasileiro um total de três mil comunidades quilombolas certificadas. Porém, este número em breve poderá ser alterado, pois o IBGE incluiu as comunidades quilombolas no censo demográfico 2020, mas adiado para 2021 por conta da Pandemia do novo Coronavírus, causador da doença COVID-19.

A Educação Profissional e Tecnológica (EPT) integra-se às diferentes etapas e modalidades de Educação e às dimensões do trabalho, da ciência e da tecnologia. Faz Educação de forma peculiar nas etapas da Educação Básica, nas modalidades de Educação de Jovens e Adultos e Educação Especial e na Educação Superior, na modalidade de Educação a Dis- 
tância.

A organização curricular da EPT é por eixo e se fundamenta a partir da constatação das tecnologias basilares de uma determinada formação profissional e seus arranjos lógicos. Ao pressupor que determinados conhecimentos tecnológicos são adequados e estabelecidos às formações profissionais, os eixos colaboram na sistematização de percursos formativos, assinalando que estes percursos podem se desenvolver tanto dentro da mesma etapa educacional, quanto na passagem de uma etapa a outra superior.

A Educação a Distância (EAD) utiliza-se dos meios e das tecnologias de informação e comunicação (TICS) para desenvolver os processos educacionais. A mediação didático-pedagógica que ocorre entre os estudantes e os professores transcorre em lugares ou tempos diversos. Observa-se que a EAD pode ser muito útil para atender os estudantes que residem ou estejam vivendo em lugares remotos. Ela pode ser implantada na Educação Básica, nas modalidades EJA e EPT e na Educação Superior.

A Educação nos Estabelecimentos Penais é ainda um assunto controverso em nosso país. Os sujeitos em privação de liberdade mantêm todos os demais direitos que a Constituição Ihes reserva, com exceção aos civis, políticos e de ir e vir livremente. Neste sentido, quando propomos a Educação em ambientes com privação de liberdade, devemos estar atentos à gestão, à articulação, à mobilização, à formação e valorização dos professores, aos aspectos pedagógicos, às propostas pedagógicas e ao financiamento da própria educação nos estabelecimentos penais.

Ela deve ser proposta para alavancar a integração social e a conquista dos conhecimentos, de forma a permitir um futuro melhor para os sujeitos em privação de liberdade quando deixarem a prisão. Assim, as ações educativas devem fazer sentido, devem influenciar de forma positiva a vida do estudante e favorecer a construção de sua identidade, ajudando-o a perceber que sua individualidade se relaciona com a sociedade e esta, com ele. A possibilidade de mudança, da perspectiva do sonho possível a ser atingido, da reintegração na sociedade, de uma nova vida, esse é o papel da Educação alargadora de horizontes.

Caracterizadas as oito modalidades de ensino, apresentamos os três princípios que deverão nortear todas as ações pedagógicas no interior da escola, conforme aponta Brasil (2013) são:

I - Éticos: envolvem os conceitos, as percepções e as ações voltadas à justiça, solidariedade, liberdade e autonomia, de respeito à dignidade da pessoa humana e de compromisso com a promoção do bem de todos, contribuindo para combater e eliminar quaisquer manifestações de preconceito de origem, raça, sexo, cor, idade, religiosa e quaisquer outras formas de discriminação, reconhecendo e respeitando as diversas identidades existentes na escola e o Mundo.

II - Políticos: abraçam o reconhecimento dos direitos e deveres de cidadania, de respeito ao bem comum e à preservação do regime democrático e dos recursos ambientais, da busca da equidade no acesso à educação, à saúde, ao trabalho, aos bens culturais e outros benefícios, da exigência de diversidade de tratamento para assegurar a igualdade de direitos 
entre os alunos que apresentam diferentes necessidades, da redução da pobreza e das desigualdades sociais e regionais.

III - Estéticos: relacionados ao cultivo da sensibilidade juntamente com o da racionalidade, do enriquecimento das formas de expressão e do exercício da criatividade, da valorização das diferentes manifestações culturais, especialmente a da cultura brasileira, da construção de identidades plurais e solidárias.

Por fim, novamente reiteramos que em toda a Educação Básica, o ponto central são os estudantes em desenvolvimento. Eles devem ser reconhecidos como sujeitos de direito e do processo de múltiplas aprendizagens, terem suas identidades culturais e humanas respeitadas e desenvolvidas nas suas relações com os demais que compõem o coletivo da sua escola, das outras escolas e da sociedade, sob a ótica da inclusão e compromisso constante com a equidade e a qualidade.

Assim, fica claro que todos os Projetos Políticos Pedagógicos das escolas deverão gerar currículos, posteriormente, propostas pedagógicas e, na sequência, práticas docentes contextualizadas que permitam o acesso, a permanência, a aprendizagem e o desenvolvimento pleno dos estudantes, fruto da Educação de qualidade social tão almejada e capaz de favorecer a reestruturação de uma sociedade mais justa.

E é neste viés que devemos pensar e conceber o Projeto Político Pedagógico, o currículo, as propostas e as práticas pedagógicas, a relação com a família, com o Estado, com a escola e tudo o que ocorre em seu interior. Sem essa ideia parece ser muito difícil consolidar políticas que efetivem o processo de integração entre as etapas e modalidades da Educação Básica, que garanta ao estudante o acesso, a inclusão, a permanência, a aprendizagem, o desenvolvimento, a conclusão das etapas e a continuidade de seus estudos.

\section{Considerações Finais}

Cremos que no decorrer do texto atingimos nosso objetivo central, que era apresentar e discutir a Base Nacional Comum Curricular, além de caracterizar a Educação Básica.

Reconhecemos que para muitos a atual Base Nacional Comum Curricular representa um avanço no processo de escolarização das crianças, adolescentes e adultos frequentadores das escolas de Educação Básica no Brasil, na medida em que sistematiza objetivos, conteúdos, procedimentos e processos de avaliação para todas as escolas, em todas as etapas e modalidade de ensino.

Todavia, para que os objetivos da BNCC possam ser atingidos, contribuindo decisivamente com o desenvolvimento e a aprendizagem dos estudantes, é condição fundamental que os professores aceitem, compreendam o documento e aprimorem seu fazer pedagógico, de forma crítica e reflexiva, questionando o que a Base significa e quais seriam realmente as funções dos conteúdos propostos. Reforcemos aqui que ela interfere na dinâmica do trabalho escolar.

Ao levarmos em conta que parte da Base foi homologada em 2017, referente às etapas 
da Educação Infantil e do Ensino Fundamental, e outra parte, o Ensino Médio, em 2018, indicamos uma cisão na ideia de integralidade da Educação Básica. Inclusive alertamos que a operacionalização da BNCC nas escolas exige um olhar mais atendo para a formação inicial e continuada dos professores que lá atuam, pois eles não desenvolveram sua formação a luz deste novo referencial.

Por fim, se desejamos uma escola de Educação Básica, com suas etapas, modalidades, princípios e currículos que colaborem para a vida democrática e digna dos seres humanos, é necessário considerar a avaliação constante da BNCC a luz de nossa realidade. Mas isso é possível?

\section{Referências}

AGUIAR, Márcia Angela da Silva. Reformas conservadoras e a "nova educação": orientações hegemônicas no MEC e no CNE. Educ. Soc., Campinas, v. 40, e0225329, 2019. Disponível em http://www.scielo.br/scielo.php?script=sciar ttext\&pid =S0101-73302019000100204\&ln$\mathrm{g}=e n \& n r m=i s o$. Acesso em: 20 abril 2021

BANIWA, Gersem. BNCC e a diversidade indígena: desafios e possibilidades. In: SIQUEIRA, Ivan Cláudio Pereira (org.). BNCC: educação infantil e ensino fundamental. São Paulo: Fundação Santillana, 2019. p. 38-55

BRASIL. Ministério da Educação. Política Nacional de Educação Especial na Perspectiva da Educação Inclusiva. Brasília: MEC/SEESP, 2008

Resolução CNE/CEB n. 7, de 14 de dezembro de 2010. Fixa Diretrizes Curriculares Nacionais Gerais para o Ensino Fundamental de 9 (nove) anos. Brasília, 2010. Disponível em: http://portal.mec.gov.br/dmdocuments/rceb00710.pdf. Acesso em: 13 março 2021.

. Diretrizes Curriculares Nacionais Gerais da Educação Básica. Ministério da Educação. Secretaria de Educação Básica. Diretoria de Currículos e Educação Integral. Brasília: MEC, SEB, DICEI, 2013

Base Nacional Comum Curricular. $2^{\mathrm{a}}$ versão. Ministério da Educação. Secretaria de Educação Básica. Diretoria de Currículos e Educação Integral. Brasília: MEC, SEB, DICEI, 2016

. LDB: Lei de Diretrizes e Bases da Educação Nacional. Brasília: Senado Federal, Coordenação de Edições Técnicas, 2017

Base Nacional Comum Curricular. Versão final. Ministério da Educação. Secretaria de Educação Básica. Diretoria de Currículos e Educação Integral. Brasília: MEC, SEB, DICEI, 2018 
. Diretrizes Curriculares Nacionais para o Ensino Médio. Brasília, 2018. Disponível em: http://novoensinomedio.mec.gov.br/resources/downloads/pdf/dcnen. pdf. Acesso em 15 de março de 2021

. Fundação Cultural Palmares. Certificação Quilombola: certidões expedidas às comunidades remanescentes de quilombos (CRQs) atualizada até a portaria $n^{\circ} 34 / 2013$. Diário Oficial da União, Brasília, 18 fev. 2019. Disponível em: http://www.palmares.gov.br/wp-content/ uploads/2015/07/certificadas-18-02-2019.pdf. Acesso em 22 de março de 2021

CALLEGARI, Cesar. A BNCC no CNE: porque foi necessário "virar a mesa". In: SIQUEIRA, Ivan Cláudio Pereira (org.). BNCC: educação infantil e ensino fundamental. São Paulo: Fundação Santillana, 2019. p. 12-24

CASAGRANDE, Ana Lara; ALONSO, Kata Morosov; SILVA, Danilo Garcia da. Base nacional comum curricular e Ensino Médio: reflexões à luz da conjuntura contemporânea. Revista Diálogo Educacional, Curitiba, v. 19, n. 60, p. 407-425, janeiro/março, 2019.

CERICATO, Itale; CERICATO, Lauri. A formação de professores e as novas competências gerais propostas pela BNCC. Revista VERAS, São Paulo, v. 8, n. 2, p. 137-149, julho/dezembro, 2018

DESCHAMPS, Eduardo. BNCC: a escola, o currículo, a diversidade do Brasil e a sociedade do século 21. In: SIQUEIRA, Ivan Cláudio Pereira (org.). BNCC: educação infantil e ensino fundamental. São Paulo: Fundação Santillana, 2019. p. 12-24

MARTINS, Dayse Marinho. Por uma história da inclusão de alunos com transtorno mental na Educação de Jovens e Adultos no Brasil. In: MONTENEGRO, Rúbia Kátia Azevedo (org.). Educação: possibilidades e caminho. Campo Grande: Editora Inovar, 2019. p. 389-401

MATOS, Giselle Fontenelle de. Formação inicial integrada ou inclusiva: o caso do curso de Licenciatura em Educação Física da Universidade Estadual de Roraima - UERR. (20 de fevereiro de 2020. 112 f.). Dissertação de Mestrado (Programa de Pós-graduação em Educação - UERR/IFRR) - Universidade Estadual de Roraima. Boa Vista, 20/02/2020

MENEZES, Suely Melo de Castro. BNCC: um diálogo aberto para a construção dos currículos e a autoafirmação da Educação Escolar Indígena. In: SIQUEIRA, Ivan Cláudio Pereira (org.). BNCC: educação infantil e ensino fundamental. São Paulo: Fundação Santillana, 2019. p. $116-129$

MINEIRO, Flávia Kaine Pereira Alves. Saberes Pedagógicos da Educação Física na Educação de Jovens e Adultos: um estudo a partir do IFRR/Campus Boa Vista. (03 de novembro de 2020. 117 f.). Dissertação de Mestrado (Programa de Pós-graduação em Educação - UERR/ IFRR) - Universidade Estadual de Roraima. Boa Vista, 03/11/2020 
MONTEIRO, Elaine; REIS, Maria Clareth Gonçalves. Patrimônio Afro-Brasileiro no Contexto da Educação Escolar Quilombola. Educação \& Realidade, Porto Alegre, v. 44, n. 2, 2019. Disponível em: http://www.scielo.br/scielo.php?script=sci_ arttext\&pi$\mathrm{d}=\mathrm{S} 2175-62362019000200406 \&$ Ing=en\&nrm=iso. Acesso em 21 de março de 2021

NEIRA, Marcos Garcia. Incoerências e inconsistências da BNCC de Educação Física. Revista Brasileira de Ciências do Esporte, Goiânia, v. 40, n. 3, p. 215-223, julho/setembro, 2018

NUNES, Cesar. Apontamentos para a produção social de uma filosofia e de uma pedagogia dos Direitos Humanos na Educação Brasileira. In: NUNES, Cesar Augusto Ribeiro e POLLI, José Renato (organizadores). Educação e Direitos Humanos: Uma Perspectiva Crítica. Jundiaí: Edições Brasil / Editora Fibra/ Editora Brasílica, 2019. p. 75-88

POLLI, José Renato. Ética e educação humanizadora a partir de Paulo Freire e Jurgen Habermas. In: NUNES, César e POLLI, José Renato (organizadores). Educação, humanização e cidadania: fundamentos éticos e práticas políticas para uma pedagogia humanizadora. Jundiaí: Editora In House e Editora Brasílica, 2018. p. 117-137

SILVA, Maria Valnice; SANTOS, Jean Mac Cole Tavares. A BNCC e as implicações para o currículo da Educação Básica. In: Congresso Nacional da Diversidade do Semiárido, 1, 2018, Natal. Anais do I Congresso Nacional da Diversidade do Semiárido. Natal. 2018

SOUZA, Adria Simone Duarte de; MENDES, Geancarla Coelho. O trabalho docente do educador do Campo e a Pedagogia da Alternância: elementos para reflexão e discussão. In: GHEDIN, Evandro (org.). Educação do Campo: Epistemologias e práticas. São Paulo: Cortez, 2012. p. 251- 270

TAGLIAVINI, João Virgílio. A Direita e o rápido desmanche do direito à Educação no Brasil. In: NUNES, Cesar Augusto Ribeiro e POLLI, José Renato (organizadores). Educação e Direitos Humanos: Uma Perspectiva Crítica. Jundiaí: Edições Brasil / Editora Fibra/ Editora Brasílica, 2019. p. $127-137$

TUTTMAN, Malvina Tania; AGUIAR, Márcia Angela da Silva. A construção da BNCC da Educação Infantil e do Ensino Fundamental: uma visão crítica. In: SIQUEIRA, Ivan Cláudio Pereira (org.). BNCC: educação infantil e ensino fundamental. São Paulo: Fundação Santillana, 2019. p. 81-94 